\title{
Consciousness in Second Language Acquisition: \\ A Review of Field Studies and Laboratory Experiments
}

\author{
Nick C. Ellis* \\ * Requests for reprints \\ N.Ellis@bangor.ac.uk \\ School of Psychology, \\ University of Wales Bangor, \\ Bangor, \\ Gwynedd \\ Wales \\ LL57 2DG \\ $\mathrm{UK}$ \\ To appear in \\ Language Awareness
}

Submitted 3 April, 1995 / Revision 24 July, 1995.

Keywords: Implicit and Explicit Learning; Consciousness; SLA; Negative Evidence;

Explicit Instruction; Artificial Languages. 


\section{Abstract}

This article addresses the roles of implicit learning, conscious hypothesis testing, and explicit instruction in Second Language Acquisition (SLA). In particular it asks (i) what is the role of consciousness in SLA, (ii) what is the role of formal explicit instruction in SLA, (iii) to what extent are the route, rate, and eventual levels of SLA affected by instruction, (iv) does focusing learners' attention on grammar facilitate SLA, (v) is there a role of negative evidence in SLA? In order to answer these questions it marshals relevant evidence from two complementary sources: (i) ecologically valid but methodologically weaker field studies of classroom SLA, (ii) methodologically stronger laboratory experiments which investigate acquisition of artificial languages. These studies suggest that although much of the acquisition of language form comes as a result of implicit learning, there are demonstrable roles for explicit learning, for explicit instruction, particularly that which involves grammatical consciousness raising, and for the provision of negative evidence and recasts. For epistemological reasons it is hard to affect the route of acquisition, but these factors can speed the rate of language acquisition and raise ultimate levels of attainment. 


\section{Implicit Learning, Explicit Learning, and Explicit Instruction}

Implicit learning is acquisition of knowledge about the underlying structure of a complex stimulus environment by a process which takes place automatically and without conscious operations simply as a result of experience of examples. Explicit learning is a more conscious operation where the individual attends to particular aspects of the stimulus array and generates and tests hypotheses in search of structure. Human learning can take place implicitly, explicitly through selective learning, or, because we can communicate using language, explicitly via given rules (assimilation of a rule following explicit instruction). The last fifteen years has evinced an explosion of psychological investigations into implicit and explicit learning (see N.Ellis, 1994a for reviews).

What of language - is it acquired implicitly or learned explicitly? Different language teaching methods assume different answers to this question (see Ellis \& Laporte, in press). But what is the evidence? This review paper will briefly assess recent field studies and laboratory research which address various aspects of this question, in particular:

- Is Second Language Acquisition (SLA) a conscious process or does it result from implicit learning?

- Is there a role of formal instruction in SLA?

- Does 'grammatical consciousness raising' (Sharwood-Smith, 1981), or input processing instruction (making certain form-meaning relationships salient by focusing learners' attention on them - e.g. Terrell, 1991; VanPatten \& Cadierno, 1993a,b) facilitate SLA?

- Does provision of negative evidence promote SLA?

\section{Implicit and Explicit Language Learning: The Role of Consciousness in SLA}

\subsection{Field Studies of SLA}

Various SLA researchers hold that attention to input is necessary for input to become intake that is available for further mental processing (Long, 1991; R.Ellis, 1993; N.Ellis, 1994b,d). Schmidt (1990; 1993; 1994) argues that the subjective experience of "noticing" is 
the necessary and sufficient condition for the conversion of input to intake in SLA, thus to acquire phonology one must attend to phonology; in order to acquire pragmatics, one must notice both linguistic forms and the relevant contextual features; etc.

In contexts of natural language acquisition it is difficult if not impossible to demonstrate that all learning requires noticing. However, there are a few field studies which usefully bear on this issue. Schmidt (1990) discusses the evidence from his own learning of Brazilian Portuguese (Schmidt and Frota, 1986) in support of the hypothesis that intake is the subset of input that is attended to and noticed, finding an extremely close connection between his recorded noticings (diary entries) and what could be shown through the analysis of taperecorded interactions with native speakers to have been learned. It is particularly compelling evidence in that it included cases in which incorrect use could be traced to specific misanalyses of what was heard in input.

This diary study has the advantage of a longitudinal design which better informs interpretation of causation - noticing was logged before performance was assessed. There is also evidence from logically weaker cross-sectional studies which attempt to correlate aspects of fluent performance with accuracy of verbalisable knowledge concerning language structure at any one point in time. Seliger (1979) tested monolingual and bilingual children and adult English as a Second Language (ESL) learners for their use of the a/an allomorphs of the indefinite article and their ability to verbalise the rule underlying their performance, finding no relationship between performance on the task and learners having a conscious rule. In contrast, Hulstijn and Hulstijn (1984) assessed second language (L2) learners' awareness of two Dutch word order rules, finding that learners with explicit knowledge had significantly higher performance scores but also that learners who were unable to verbalise the rules performed at better than chance levels on one of the structures tested. Green and Hecht (1992) also demonstrate this dissociation between awareness and performance. German ESL learners were asked to correct twelve common errors and state the rules that were violated. Results indicated that if learners had the correct rule explicitly available then they could produce a correction in nearly every case, suggesting a link between rule knowledge and performance. However, formal grammar teaching did not guarantee that 
learners would learn the rules that were taught, and learners produced many corrections even when they could not articulate the rules or gave incorrect rules. Some pedagogical rules were relatively easy to learn, including those that referred to easily recognised categories, and could be applied mechanically. Rules that were more difficult to learn involved aspect or other subtle semantic distinctions and those not governed by the immediate linguistic context.

Weighing these findings in the balance, it appears that (i) explicit knowledge and implicit performance are correlated, with explicit knowledge generally being associated with better performance, but (ii) there may be instances of implicitly acquired fluent performance in the absence of explicit verbalisable knowledge of the underlying rule structure. This may particularly be the case for structures which are less obvious or salient.

However these key issues of consciousness and salience are essentially too intractable to be properly assessed in naturalistic situations and are better pinned down in the laboratory.

\subsection{Laboratory Studies involving Learning Artificial Languages}

Any theory of implicit learning of language must demonstrate (not simply assume) that learners lack conscious awareness of syntactic patterns during acquisition. And, more difficult still, for any particular grammatical pattern it is necessary to show that the learner has never consciously analysed it. It is difficult enough to properly determine just what people are aware of at any particular time. It is even more difficult to keep a record of the contents of their consciousness throughout their learning experiences. It is impossible to exhaustively log the on-line contents of language learners' consciousness in real-world learning situations. For these reasons questions concerning the role of consciousness in language learning have been studied with more empirical control using artificial languages or grammars (for reviews see Reber, 1993 and readings in N.Ellis, 1994a). It will become clear that the experimental rigour of artificial grammar studies does not come free. It is won at the cost of ecological validity. Artificial languages are usually devoid of referential or social meaning; they are usually learned over short periods of an hour or two; unlike SLA, there is little role of transfer from L1 in their acquisition; and they are learned as experimental tasks rather than in naturalistic situations as a means to communicate. But 
notwithstanding these differences which are particularly pertinent to those who espouse the view that natural languages are cognitively specific phenomena which are acquired differently from other types of knowledge system, theories based on artificial language experiments address similar issues to those of SLA, and, as we will show, they reach broadly similar conclusions while better supporting them with more rigorous empirical foundations.

The artificial languages so studied differ in their complexity.

\section{Simple Rule-based systems}

The earliest investigation used Miniature Linguistic Systems (MLSs) which consist of two-part stimuli and associated two-part responses (e.g. red circle -> 'zin-tep'; yellow circle $>$ 'jor-tep'; red triangle -> 'zin-fub'; etc.). These were originated by Esper (1925) who found that if cells were omitted during the learning phase (e.g. yellow triangle from the above examples) the subject was able to correctly respond (jor-fub) to these two stimuli during testing, often without realising the stimuli were novel. Foss (1968), exploring such MLSs further, found that systematicity had a strong effect on the learning process: subjects presented with rule-based pairings learned a rule that enabled them to analyse stimuli and responses and to generalise to novel stimuli; yet often they were not consciously aware of this systematicity or 'rule'. In contrast, subjects presented with arbitrary pairings only learned the stimulus-response pairs as isolated items and were rarely able to generalise.

Thus subjects search for structure even in random arrays, if there is systematicity they can unconsciously apprehend it, and this new knowledge can be applied to novel stimuli.

\section{Complex Rule-based systems}

Reber (1969) developed a new task which was more similar in complexity to that of a grammarian: an artificial language consisting of a set of well formed strings that could be generated by a set of simple rules. Such finite state languages are formally simple but psychologically complex since the underlying grammars are not readily apparent from their surface forms. In these experiments subjects were exposed to strings of letters (e.g., MXRMXT, VMTRRR) generated by an underlying rule system, usually a finite-state system (Markov grammar) that produces strings of symbols in a left-to-right, non hierarchical fashion. In many experiments (see Reber, 1993 for review), groups of subjects were exposed 
to such input with either (i) instructions to try to figure out the rules for letter order or (ii) instructions to memorise the examples for a memory test. The acquisition phase, typically a few hours but sometimes longer, was followed by a testing phase to assess what subjects had learned. This phase required subjects to identify new letter strings as grammatical (i.e. generated by the rules of the underlying grammar) or ungrammatical (items that violate the grammar). The testing phase in some experiments also included probing subjects' awareness in order to find out whether they had discovered and could verbalise the underlying rules of the system. The basic findings from such experiments were:

-Through simple exposure to exemplars, subjects become sensitive to underlying regularities in input and can accurately characterise new strings which they have never seen before as grammatical or ungrammatical at above chance levels.

-They are generally unable to verbalise the rules of the underlying grammar used to generate the strings.

Thus Reber claims that subjects implicitly learn such artificial grammars: information is abstracted out of the environment without learners' recourse to explicit strategies for responding or explicit knowledge of the system, and their implicitly learned information can be applied efficiently in transfer recognition tasks.

But what happens if subjects are encouraged to explicitly search for the underlying rules? Explicit Search for Rules.

Reber (1976) investigated this effect of instructional set on implicit learning of an artificial language. Here one group of subjects was given neutral implicit instructions and the other was given general information about artificial grammars and encouraged to undertake an explicit search for rules. He found that although both groups could discriminate grammatical strings from non-grammatical strings the implicit group could do so much better than the explicit group. The explicit group were poorer at memorising exemplars from the language, they learned less about the underlying structure despite being taken to the same learning criterion, and they had a tendency to invent rules which were not accurate representations of the structure. In this experiment the complex structure was too rich to be explicitly analysed by the subject in the short time allowed and the explicit instruction to search for rules disrupted 
performance as subjects searched in vain and elaborated irrelevant rule systems, which in turn masked the implicit learning processes.

Yet this is not invariably the case. Reber, Kassin, Lewis and Cantor (1980) compared explicit and implicit learning instructions as a function of complexity of the stimulus display of an artificial grammar. In one experiment subjects received either neutral instructions telling them simply to try to memorise the strings of letters or explicit instructions telling them that the letter strings were rule-governed and that discovering these rules would assist them in the memorisation task. Half of each group was then presented with a large array of letter strings from the grammar arranged haphazardly; the other subjects saw the same strings but arranged in a systematic manner that reflected the underlying structure of the grammar. To appreciate this latter arrangement note that the grammar used has several "foundation" strings; e.g., T(S)XS and P(T)(VPX(T))VV where parentheses mark loops or cycles of the grammar. The foundation string T(S)XS generates strings of the form, TXS, TSSXS, and TSSSSXS; the foundation string $\mathrm{P}(\mathrm{T})(\mathrm{VPX}(\mathrm{T})) \mathrm{VV}$ generates strings of the form: PVV, PTTTPVV, PTVPXVV, and PVPXVPXVV. The structured display had all the strings based on each foundation string grouped together in a column, while the random group saw the strings in a random order of presentation.

Reber et al. (1980) found that the explicit instructions were helpful when subjects worked with the structured display; but they were useless or detrimental when the display was haphazard. Clearly, explicit and implicit modes of learning interact with the nature of the display.

Berry and Broadbent (1988) reach similar conclusions from investigations of subjects learning complex control tasks. They distinguish between two types of learning; unselective (implicit) and selective (explicit). In an unselective mode many possible variables are stored by the learner and only through experience will condition-action links become established allowing effective performance. This process is slow and usually results in inaccurate verbal knowledge. The selective mode means only a few variables are chosen and the contingencies between them are studied by the learner. If the correct variables are chosen then this is a 
speedy process and leads to knowledge that can be made explicit. Of course if the wrong variables are selected then this slows down the process.

These ideas parallel Reber's explanation of the Reber et al. (1980) findings. He attributes the interaction of implicit/explicit learning mode and structure of learning presentations to one variable: salience, i.e. the degree to which the critical pattern of letter ordering that make up the language are "obvious". If the stimulus array's structure is simple then the likelihood of inducing appropriate rules increases and explicit learning is optimal; if the displays are more random explicit subjects' search for obscure rules results in the worse performance than implicit learning.

In summary, when the material to be learned is relatively complex but there is only a limited number of variables and the critical features are salient, then learners gain from being told to adopt a selective mode of learning where hypotheses are to be explicitly generated and tested and the model of the system updated accordingly. As a result they are also able to verbalise this knowledge and transfer to novel situations. When the material to be learned is more randomly structured with a large number of variables and where the important relationships are not obvious, then explicit instructions only interfere, and an unselective mode of learning is more effective. This unselective learning is instance-based but, with sufficient exemplars, an implicit understanding of the structure will be achieved. Although this knowledge may not be explicitly available, the learner is nonetheless able to transfer to conceptually or perceptually similar tasks.

\section{With simple rule systems}

- Both implicit and explicit learning is possible.

\section{With complex rule systems}

- Attention to exemplars can result in implicit learning.

- Analytic/ selective/ 'explicit' learners searching for structure and rules will do well if there are a limited number of variables and the criterial features are salient.

- Unanalytic/ unselective/ 'implicit' learners will do well with more random material where the structure is more complex and the criterial features are less salient. 


\section{Is there a Role for Formal Explicit Instruction in SLA?}

\subsection{Theoretical Issues}

Before we assess the available evidence concerning the effectiveness of explicit instruction on SLA, we should first clarify the relevant outcome measures. What aspects of SLA are we concerned with - route of acquisition and developmental sequence, rate of acquisition, \&/or eventual levels of accuracy and fluency?

\section{Routes of Acquisition}

Language development follows well defined developmental sequences. Children first utter single words and then holophrases before they begin to use rudimentary positional grammar; active structures appear before passive ones; etc. With increasing competence, so mean length of utterance and structural complexity increases. The natural developmental sequence is well charted and remarkably consistent across native learners: there is a fixed sequence of overlapping stages, each characterised by the relative frequencies of structures, which learners apparently have to traverse on the way to complete mastery of language (Crystal, 1987). Many skills are like this, indeed so much so that the phenomenon is crystallised in the English language: trying to break a natural order is 'trying to run before you can walk'.

Pretty much the same developmental sequences are found in L2 interlanguage acquisition (Johnston, 1985; the Natural Order Hypothesis in Krashen \& Terrell, 1982). For example, just as a young child goes through $N o+X$ ('no is happy'), before no/not/don't $V$ ('they not working'), before analysed don't ('she doesn't live there') in the acquisition of English negation, so also do Spanish, Japanese, and other ESL learners (Schumann, 1979). Long (1991, p. 42) summarises the general point as follows: "the same developmental sequences are observed in the ILs of children and adults, of naturalistic, instructed and mixed learners, of learners from different L1 backgrounds, and of learners performing on different tasks... Passage through each stage, in order, appears to be unavoidable... As would be predicted if this definition is accurate, it also seems that developmental sequences are impervious to instruction."

Various zero-option positions take this lack of effect of instruction on developmental sequence as their justification for eschewing all instruction in SLA (e.g., Dulay \& Burt, 1973; 
Krashen \& Terrell, 1983; Prabhu, 1987). Chomsky used the same argument to support the idea that language is an independent faculty separate from non-linguistic cognitive abilities: "As far as we know, the development of human mental capacity is largely determined by our inner biological nature. Now in the case of a natural capacity like language, it just happens, the way you learn to walk. In other words language is not really something you learn. Acquisition of language is something that happens to you; it's not something that you do. Language learning is something like undergoing puberty. You don't learn to do it; you don't do it because you see other people doing it; you are designed to do it at a certain time." (Chomsky, 1988, pp. 173-174).

However, we need to clarify the natural in Natural Order: does it refer to human biological nature or the nature of the world? It is too easy to slip into the erroneous belief that invariance of sequence of development is a necessary and sufficient index of innately-given skills like walking. It is indeed a characteristic of innate skills, but so also does it apply to a wide range of learned abilities. For example, we are neither innately pre-programmed to read nor to do arithmetic - both have appeared too late in our cultural development to be evolutionarily-given - yet there are characteristic stages of reading development (logographic then alphabetic then orthographic - see Frith, 1985; N.Ellis, 1994c), and in mathematics (counting precedes addition precedes multiplication precedes integration, etc.). Sequences of development are as much, or even more, a consequence of epistemology, the structure of knowledge in the relevant problem-space, as they are learners' biological processing capacity and neural development. Invariant developmental sequences of language acquisition are essentially interesting because they inform us about how languages work, how they are represented, and how more complicated structures arise from simpler, more basic forms. They are as consistent with empiricist as with linguistic nativist theories of language.

This does not deny the question of 'effect of instruction on route of acquisition' as an important empirical issue, but it does weaken the logical role of any null answer in either denying any involvement of consciousness in language acquisition (L1 or L2) or implying innate language acquisition devices. 


\section{Rate and Accuracy}

Even if the structure of language entails that there are fixed stages of acquisition, there remain the separate issues of whether instruction can affect rate of acquisition or ultimate levels of accuracy.

\subsection{Field Studies of SLA}

\section{Routes of Acquisition}

It has repeatedly been demonstrated that there is little or no effect of instruction on route of acquisition. Studies of L2 morphology and especially of L2 syntax indicate that the overall sequence of acquisition is the same in classroom and naturalistic settings (Long, 1991; R.Ellis, 1994 for reviews). For example, morpheme accuracy orders and developmental sequences do not reflect instructional sequences (Lightbown, 1983; R.Ellis, 1989), and tuition in a German SL word order structure beyond students' current processing abilities has been shown not to result in acquisition (Pienemann, 1984).

\section{Rate and Accuracy}

Adequate evaluation of explicit teaching on rate of SLA is difficult because comparisons of the effectiveness of one or two years of training of one type or another are confounded by the content of these years varying in all attendant factors such as amount of exposure, comprehensibility of input, pragmatics, motivation and affect. There is insufficient space here to go into the necessary detail on all of the relevant studies, and the reader is referred to the more comprehensive meta-analytic comparisons of exposure methods with those involving exposure and instruction (Long, 1983; R.Ellis, 1990). Long (1983) reviewed eleven studies relevant to instructional effects and concluded that there is sufficient evidence to indicate that classroom instruction is more effective than exposure in promoting L2 acquisition, (i) for children as well as adults, (ii) for intermediate and advanced learners as well as beginners, (iii) on integrative as well as discrete-point tests, and (iv) in acquisition-rich as well as acquisition-poor environments. R.Ellis (1990, 1994 chapter 14) collates additional studies 
reported since 1983 and similarly concludes that although grammar instruction may prove powerless to alter the natural sequence of acquisition of developmental structures, (i) it can be effective in enabling learners to progress along the natural order more quickly, (ii) grammatical features that are not subject to developmental constraints may be amenable to instruction, (iii) even in situations where formal instruction fails to enable learners to use structures in production it may nevertheless help learners to comprehend their meaning.

Thus there are many demonstrations that formal instruction can affect SLA. However, there are also reported studies which fail to demonstrate any generalised or lasting effect. The following three studies are illustrative. (1) Schumann (1978) found instruction affected structures elicited in test-like situations, but not in normal communication. (2) Lightbown, Spada and Wallace (1980) reported that while overall scores in a grammaticality judgement task administered immediately after instruction increased an average of almost 11 per cent, the scores on a second post-test five months later fell back to prior levels. They suggested that “improvements ... were based on the application of knowledge temporarily retained at a conscious level, but not fully acquired" (p. 166). (3) Terrell, Baycroft and Perrone (1987) investigated the effects of instruction on the forms and uses of the Spanish subjunctive mood in English speaking students taking a first year course in Spanish at university level. Their results indicated that in spite of concentrated instruction on the forms and uses of the Spanish subjunctive, learners were unable to use the mood correctly in free conversation. Although correctness levels on written tests averaged $>90 \%$, students only rarely surpassed $10 \%$ accuracy levels in conversation. Terrell, Baycroft and Perrone concluded that the students were not able to use the subjunctive in spontaneous conversation due to their inability to monitor their conversational output with the grammatical information that they had learned. In Krashen's terminology, the students had "learned" the rules but they had not yet "acquired" them. Such results caution that explicit instruction can too simply result in students having explicit knowledge which is dissociated from, and which fails to affect, their fluent implicit performance. The challenge is to achieve this influence. The studies reviewed in Long (1983) and R.Ellis (1994) demonstrate that this can be done. What is next needed is 
to determine the conditions which optimise the interface - issues which we will return to subsequent sections.

'Formal instruction' is too catch-all a category, as 'method' is too poorly defined a term (Long, 1991), to allow much sense from putting all of these studies in the same meta-analysis and reviewing them together. We are only just beginning to gather a sufficient quantity of studies to allow us finer categories of comparison where we can investigate the effects of particular methods of instruction with particular content and focus on particular outcome measures (fluency vs. accuracy, comprehension vs. production, etc.) in particular learners of particular learning styles at particular stages of development (e.g. Long, 1988). Indeed this is the ultimate goal of SLA research and it has a long way still to go. But there is already evidence to suggest that these are the important factors which qualify the potential effectiveness of instruction.

\section{Teachability}

These dissociable influences of instruction on route and rate of acquisition are central to the Multidimensional Model of SLA (Meisel, Clahsen and Pienemann, 1981). This holds that SLA follows an ordered sequence of developmental stages but also that there is variation within each stage. The model distinguishes between two sets of linguistic features: developmental features which are constrained by developing speech-processing mechanisms, and variational features which are not. Pienemann, Johnston and Brindley (1988) describe each point in the developmental sequence in terms of learners' competence at processing syntactic elements in grammatical strings, and they argue that acquiring the operations involved in any one stage entails competence to perform the operations of the immediately preceding stage. Acquisition is thus viewed as a continuous process in the sense that learners continue to work on the processing operations involved in one stage while beginning to acquire those involved in the next stage. Thus it is impossible for the L2 learner to skip over a stage in the acquisition process.

Research on the Multidimensional model (e.g., Pienemann, 1984, 1985, 1986; Pienemann and Johnston, 1987) aimed at investigating whether formal instruction is powerful enough to alter the sequence of acquisition has led to the Teachability Hypothesis 
(Pienemann, 1985, 1987) which states: "Instruction can only promote language acquisition if the interlanguage is close to the point when the structure to be taught is acquired in the natural setting." (1985, p. 37). The teachability hypothesis denies any possibility that instruction can alter the natural route of development of developmental features. However, as Pienemann (1987b) points out, this negative constraint does not imply that instruction has no effect on acquisition whatsoever. Rather, instruction can facilitate SLA processes if it occurs when the learner is ready, i.e. if the interlanguage development of the learner fulfils the requirements for such an influence. If this condition is met then instruction can also improve acquisition with respect to (i) the speed of acquisition, (ii) the frequency of rule application and (iii) the different contexts in which the rule has to be applied. In addition, the teachability hypothesis also allows for the positive effect that instruction can have on the acquisition of variational features.

\subsection{Laboratory Studies involving Learning Artificial Languages}

\section{Explicit instruction in Simple Rule-based systems}

Danks and Gans (1975) investigated how instructing subjects in the rules affected acquisition in simple rule-based systems like those used by Foss (see section 2.2). Subjects were shown the rule matrix used to construct the stimulus-response pairs at different points of the experiment: (1) before learning, (2) halfway through learning, (3) after learning, or (4) not at all. Explicit presentation of the rule during learning accelerated acquisition of the pairs. Although the 'after' and control groups could learn the structured material, they needed more practice. The brief presentation of the rule matrix did not give subjects enough opportunity to learn all the specific associations yet, despite their protests that the rule matrix had confused them, the data showed that the brief viewing of the rule was beneficial. Although all subjects could respond accurately to the old items, presentation of the matrix did affect responding to new items since the 'after' group performed no differently to the subjects who had never seen the rule matrix and they did far worse than the subjects presented the rule early in the learning process. Therefore early presentation of the rule matrix increased acquisition of stimulus-response pairs and enabled the subjects to generalise to new stimuli. 
Danks and Gans suggested "First the subject must learn that a rule that maps stimuli onto responses does exist. Second he must learn the structure of that rule... Third the subject must learn the content of that rule, or the specific associations" and further explored this by presenting four groups of subjects with varying types of information regarding the rule matrix, the instructions relating to the three above components (rule existence, structure, content). Simply telling a subject that a rule was involved had no facilitating effect either on learning or their use of that rule. The overall performance of this group was worse, but not significantly so, than the control group, which suggests that explicit search for rules can actually hinder performance (as described in section 2.2, this result will be qualified by the salience of the structural properties). However both 'content' and 'structure' subjects benefited in their acquisition and use of the rule.

In conclusion, explicit instruction that a rule exists is not necessarily sufficient to enhance acquisition, but explicit instruction as to the content and structure speeds up the learning process. For maximal effect with explicit instructions the information should be presented during the learning phase.

\section{Explicit Instruction in Complex Rule-based systems}

Reber et al. (1980; experiment 2) investigated the effects of explicit instruction on the acquisition of complex artificial grammars (AG). Subjects in the implicit (I) group were asked to observe closely a large set of exemplars from the AG, a procedure that earlier work had indicated is sufficient for subjects to learn (implicitly) a good bit about the underlying structure of the grammar. Subjects in the explicit-only (E) group were provided with complete knowledge of the underlying $\mathrm{AG}$ by the simple device of giving them an instructional session involving a schematic of the underlying rule system and showing them how the grammar generated letter strings. They were also required to generate several strings themselves to ensure that they understood how the AG worked. There were three other groups of subjects who had both explicit instruction and the same amount of exposure to instances as the I group. One-third of the these subjects were given the explicit training before the observation phase (EI), one-third had it in the middle (IEI), and one-third after the observation session was complete (IE). Following this training all subjects were run through 
the standard well-formedness task where they had to determine the grammatical status of novel strings.

Performance on the grammaticality task was ordered as follows: EI $(76 \%)>$ IEI $(71 \%) \approx$ IE $(70 \%)>\mathrm{I}(62 \%) \approx \mathrm{E}(66 \%)>$ chance $(50 \%)$, i.e. grammatical accuracy was directly related to the point in time that the explicit instructions were introduced, the earlier the better. The point is simple, if explicit instructions are given at the outset then the appropriate structural relations are made salient, subjects set themselves to process information in particular relevant ways and are facilitated in the observation of the exemplars. In contrast, subjects who are left to their own devices will induce representations that are legitimate reflections of the stimulus displays (as indicated by the success of observation-only implicit subjects) but these representations are not necessarily complete descriptions of the AG. Indeed, as we know from other work (Dulany, et al., 1984; Perruchet \& Pacteau, 1990; Reber \& Lewis, 1977), they are likely to be building representations based on smaller chunks made up of two and three letter groups.

N.Ellis (1993) investigated the effects of three different types of instruction and language exposure on the learning of a complicated morphological rule structure of Welsh, the soft mutation. During exposure the subjects' task was to learn the English L1 translation equivalents of Welsh phrases which incorporated examples of mutations. 'Random' learners, the operational definition of more implicit, naturalistic exposure, saw randomly ordered instances. 'Rule' learners were first explicitly instructed in the content of the soft-mutation rule system and they explicitly learned these rules before being exposed to the language. 'Rule\&Instances' learners saw a more structured blend of rules and examples of their use where every statement of a rule was followed by two phrases which gave examples of its application. In this case the rule statement made the use of this structure in L2 more salient. Initial learning, generalisations to new words and constructions, implicit fast performance in a reaction time (RT) well-formedness decision task, and explicit knowledge of the rules were recorded. Analyses of over 71,000 language trials demonstrated that: (1) 'Random' learners quickly achieved competence on original learning material, but showed little implicit learning, performing poorly on well-formedness (or 'grammaticality') judgements, and 
showing little explicit knowledge of the underlying rule-structure. (2) 'Rule' learners took many trials to learn the rules but this facilitated their understanding of the natural language. Unfortunately, they often knew rules explicitly yet failed to apply them in practice. (3) Initially 'Rule\&Instances' learners learn slowest. However, they alone abstracted a working knowledge of soft-mutations. When exposed to new constructions they generalised and were able both to explicitly formulate the new rules and to succeed on implicit well-formedness judgements. The first two findings clearly demonstrate the potential double-dissociation between explicit and implicit knowledge. However, the performance of the structured learners also shows that that these two types of knowledge can be brought to into mutual influence or 'interface'.

De Keyser (in press) compares the effects of explicit instruction in grammar rules and implicit learning as a function of the type of underlying systematicity (categorical rules vs. fuzzy prototypicality patterns) in an artificial language, Implexan, which subjects learned from computer exercises where they studied sentence-picture pairs over 20 learning sessions of 25 minutes each. Implexan has a lexicon of 98 words and five different morphological rules. Some of these rules were categorical (e.g. plural marking on nouns (-on) and gender marking in verbs (-in) in Implexan A), whereas others showed prototypical allomorphy (e.g. object marking on nouns (-is/-us) and plural marking on verbs (-at/-it)). Like Berry \& Broadbent (1988) and Reber et al. (1980 experiment 1), De Keyser was interested in the way in which the comparative effectiveness of implicit/explicit learning was modified by the salience of the underlying structural properties, but De Keyser's research focuses more on explicit instruction than explicit learning. Implicit learners simply studied Implexan sentences and the pictures which they described. Explicit-deductive learners had additional instruction which comprised ten minutes' study of statements of the grammar rules of Implexan before the second, third and eleventh sessions of exposure. The categorical rules were succinctly stateable, e.g. "Implexan forms the plural of a noun by adding -on to the stem. For instance the plural of perakt (book) is perakton, the plural of pemekt (clown) is pemekton." In contrast the prototypical allomorphs, as for natural language, took much more explaining: "The plural of the verb in Implexan is formed by adding -at or -it to the stem. Compare pemekt wost (the 
clown is reading) pemekton wostit (the clowns are reading). Compare pemekt dufk (the clown in driving) pemekton dufkat (the clowns are driving). There are no fool-proof rules that can tell you how to choose between -it and -at. But there are some good rules of thumb: when the verb ends in a single consonant, the plural ending is almost always -it. When the verb ends in -ust, the plural ending is always - at. In all other cases, that is, when the verb ends with a combination of consonants, but not in -ust, it is harder to choose between -it and -at. But -at is used for the majority of those verbs, and the more the end of the stem resembles -ust, the more likely it is that the ending will be -at. The verb is always plural when the subject is in the plural." I quote this at length because it demonstrates just how complicated some 'pedagogical rules' can be. How much of it can you remember from reading it once? And how much after ten minutes' study? And how much does it make sense without considerable exposure to the language? Yet this is by no means a ridiculous extreme of the type of grammar description which is necessary to explain fuzzy rules of natural language grammar (compare, for example, grammatical descriptions of how English forms the past tense or the structural clues to French noun gender). Learners' performance showed a significant advantage of explicit instruction on production of new generalised forms of sentences using the easily-stated categorical rule. Effects of instruction on the fuzzy rules was more mixed: explicit instruction resulted in productions which more often used one or other of the appropriate markers (e.g. choosing -at/-it as a plural verb marker), but choice between these two options for which one was appropriate for which particular verb stems seemed better in the implicit learning groups (although numbers were too small to allow significance testing on this contrast).

These results of these experiments (Reber et al., 1980; N.Ellis, 1993; De Keyser, in press) suggest that implicit and explicit modes of operation interact in interesting ways. Perhaps the best gloss on this interaction is that given by Mathews et al. (1989) who characterised it as synergistic in that the conscious and unconscious processes are co-ordinated in a way such that the totality of the cognitive processes associated with the acquisition of complex knowledge of complex displays is richer and more sophisticated than it could be if but one or 
the other of the systems operated totally independent of the other (see readings in N.Ellis, 1994 for further theoretical discussion of these interactions).

The practical conclusions are more straightforward. The results of Reber et al. (1980 experiment 2) with AGs, like N.Ellis' (1993) controlled study of the acquisition of Welsh morphology, demonstrate that a blend of explicit instruction and implicit learning can be superior to either just explicit instruction or implicit learning alone. Explicit instruction on its own may indeed result in verbalisable rules which the subject can state but which are not reflected in their performance, like case of "P" (Krashen and Pon, 1975), who had "learned" rules like the third person singular "-s", but was not able to use them in casual conversations because she had not yet "acquired" them (see also Krashen, 1982, 1985; Seliger, 1979). Implicit learning on its own can result in the slow acquisition of partial descriptions of the underlying structure. But early explicit rule instruction which makes salient particular patterns in the surface form can affect the learners' subsequent processing of language exemplars so that they are more likely to acquire the underlying systematicity.

In conclusion, it is clear that the advantages of explicit instruction depend on a wide range of factors: whether the learner already has the language representations which are necessary foundations for the new structure, the type of underlying rule structure, its salience, the clarity, intelligibility, and memorability of the explicit statement of the rule, and the way in which the rule is married to examples, etc. There is a clear need for further theoretical clarification of the factors which moderate the effectiveness of explicit instruction (see Hulstijn and De Graff, 1994, for a useful starting classification in terms of (i) rule complexity, (ii) rule scope and reliability, and (iii) retrieval of learned examples vs. rule application) and for further experimental research into these issues.

However, in the interim, the experimental studies reviewed here are alike in their theoretical interpretations which emphasise that an important role of explicit instruction lies in affecting the salience of structural patterns by directing learners' attention towards them. The next section will investigate these processes of 'grammatical consciousness raising' in more detail. Whatever the mechanisms, the practical conclusions of these studies concerning the effectiveness of explicit instruction are as follows: 


\section{With simple rule systems}

- Early instruction in rule structure and content facilitates acquisition.

\section{With complex rule systems}

- Explicit instruction can facilitate acquisition. If there is to be explicit instruction then with complex material it is better to explain the structure and content of the rules than merely to alert the learner to their existence.

- It is better still to do the explicit instruction early on in the acquisition process and to conjoin abstraction and instances by demonstrating the rules in operation with a number of illustrative exemplars which highlight and make more salient their application.

\section{Does Focusing Learners' Attention on Grammar Facilitate SLA?}

\subsection{Theoretical Issues}

Seliger (1979) proposed that pedagogic rules have a role in L2 instruction, not by coaching output practice, but by focusing attention on structural patterns in order to facilitate implicit learning. This idea now features in an impressive range of contemporary input-oriented theories of instructed SLA (R. Ellis, 1990, 1993, 1994; Long, 1988, 1991; Rutherford, 1987; Schmidt, 1990, 1993; Sharwood Smith, 1981, 1993; Terrell, 1991; VanPatten, in press, VanPatten \& Cadierno, 1993a,b). The underlying argument is that attention to target language forms is necessary and they will not be acquired unless they are noticed (Schmidt, 1994), therefore instruction can usefully increase the salience of target language forms in input, thus making them more likely to be noticed.

Terrell (1991) is an illustrative case. He characterises explicit grammar instruction (EGI) as "the use of instructional strategies to draw the students' attention to, or focus on, form and/or structure" (p. 53). His "binding/access framework" postulates that learners' primary motivation is to understand language and therefore that the acquisition of grammatical form comes as a result of establishing a connection between meaning and form - they are not acquiring grammatical rules, but rather individual meaning-form relationships. Three different ways are suggested in which EGI can facilitate this: 
1. As an advance organizer, by providing the learner with comprehension strategies that highlight key grammatical elements that the learner should attend (e.g. "Spanish uses a device called grammatical gender for nouns and adjectives. What this means is that the ending of some adjectives like the Spanish words for big, old, and pretty will change. For example, the Spanish word for pretty is bonito or bonita, depending on the grammatical gender of the word being described as pretty". (Terrell, 1991, p. 59).

2. As a meaning-form focuser for relations that are not salient or essential for understanding the meaning of an utterance. While some grammatical meaning-form relationships are both salient and essential to understanding the meaning of an utterance (e.g. Spanish interrogatives 'qué' (what?) and 'quién' (who?)), others are not (e.g., grammatical particles and many inflections). Inflections marking grammatical meanings such as tense are often redundant since they are usually accompanied by temporal adverbs which indicate the temporal reference. The high salience of these temporal adverbs leads L2 learners to attend them and ignore the grammatical tense verb morphemes. Terrell recommends EGI as a way of making the inflections more salient by firstly explaining their existence and secondly by providing meaningful input that contained many instances of the same grammatical meaningform relationship (again binding rules and instances as in N.Ellis, 1993, described above).

3. By providing grammatical information that can be used by the "monitor". In Krashen $(1982,1985)$ explicit knowledge can only be used as a monitor, i.e. an editor to correct output after it has been initiated by the acquired system. Terrell sees an additional role for this feeding back on acquisition: explicit knowledge helps the learner to produce more accurate and more complete L2 sentences, but, because this very output can serve as input to the acquisition process, it can also can become intake (see also Dickerson 1984; SharwoodSmith, 1981).

\subsection{Field Studies of SLA}

VanPatten and Cadierno (1993a,b) report a randomised control comparison of input processing and traditional instruction on English learners of Spanish non-SVO strings. The control group received no instruction. The processing instruction group received instruction 
which involved teaching the subjects how to counteract the SVO=agent-action-object strategy - it made salient and had subjects respond to the meaning of OV strings, but "at no point did processing instruction involve the production of the pronoun forms by the learners" (pp. 48-49). The traditional instruction group received instruction which involved presenting explanations concerning the form and position of direct object pronouns and then giving learners practice in how to make sentences with these pronouns. A pretest / post-test procedure (with immediate as well as delayed post-tests and both interpretation and production tasks) was used. The results showed (i) for the interpretation task, the processing group's scores were significantly higher than those of the other two groups, with no significant difference between traditional and control groups; (ii) for the production task, the traditional and the processing groups' scores were about the same and both were significantly higher that those of the control group. VanPatten and Cadierno conclude (i) making form/meaning relations salient can facilitate their acquisition, (ii) processing instruction impacted both on how subjects processed input and on what they could access for production, (iii) traditional instruction, on the other hand, affected what learners could access for production, but seemed to have little impact on how they processed future input.

Doughty (1991) compared the effects of 'meaning-oriented instruction' and 'rule-oriented' instruction on the acquisition of relative clauses. Adult ESL students read texts presented sentence-by-sentence by computer. For ten days they read five or six sentences, each containing the target structure, object-of-preposition type relative clauses. The sentences made up three coherent stories. The "exposure only" group simply read the texts, a "meaning-oriented" group (MOG) received "lexical or semantic rephrasings and overall sentence-clarification ..." (p. 448) on the lower part of the screen, and a "rule-oriented" group (ROG) received an "animated grammar" program that "provided instruction on relativization through a combination of explicit rule statement and on-screen sentence manipulation" (p. 448). All three groups had daily comprehension testing, and took pre- and post-tests focusing on the target structure. The results showed that (i) the meaning-oriented group demonstrated an advantage with regard comprehension of the content of the text, and (ii) both the meaningoriented and rule-oriented groups outperformed the control group in their ability to relativize. 
Given that the ROG were receiving input enhancement (Sharwood-Smith, 1993) without extra output practice, this result suggests that these effects of rule-oriented instruction resulted from of increasing salience in input.

Alanen (1992) reported a randomised control study of the learning of semi-artificial Finnish as a second language, in which the learning targets were two locative suffixes and a rule of consonant gradation. One contrast compared a control group who was simply exposed to input containing the target structures with those who were given explicit rule statements. In line with the results of section 3.3, explicit instruction learners showed superior later production of the grammatical forms under test. The study also investigated input enhancement by comparing a group for whom the target structures were italicised with the simple exposure control. Alanen hypothesised that those receiving enhanced input would learn better than controls because the italicisation of target structures would increase these structures' salience and cause them to be noticed. The results were mixed. When subjects were scored for their ability to produce the correct target suffixes -lla and -ssa after training, there were no significant differences between the two groups, although analysis of their productions showed that subjects in the control group were likely to omit the suffixes altogether, whereas most subjects in the enhanced input condition produced incorrect variants such as -ousa, -ous, -osi, -osso, -asso, -sse, and -sa (all for -ssa), suggesting that italicisation had caused them to notice the presence of the suffix but was insufficient for them to acquire the exact form. However, some subjects in the control group produced correct suffixes, indicating that they may have noticed the forms without enhancement of the input. This possibility could not be confirmed directly from the data for every case, but there were positive correlations between the performance of all subjects on post-tests and the number of comments in think-aloud protocols which indicated that these target forms were being noticed when processing the input.

These three studies alike support a role of 'grammatical consciousness raising' on SLA even in the absence of output practice. 


\subsection{Laboratory Studies involving Learning Artificial Languages}

The same conclusion is warranted from AG research. The studies reviewed in section 3.3 all manipulated input salience while holding constant across groups the amount of output practice. In all cases explicit instruction which made structural relations more salient resulted in better language acquisition.

\section{Negative Evidence in SLA}

There are now a number of demonstrations both that negative evidence is provided for learners and that they do indeed use it. Learners' attention to, and immediate use of, feedback was demonstrated by Chaudron (1977) who analysed student performance in the classroom to show that they are able to repair an utterance after a teacher had corrected it. The teacher corrections that worked best in this respect were those which clearly indicated to the student the locus of the error by, for example, prosodic \&/or intonational cues. More recently, Pica (1988) reported that beginning ESL acquirers, in response to interlocutors' signals of noncomprehension, modified their spoken output $31 \%$ of the time in a way that made the utterance closer to correct English, while intermediate acquirers did so $51 \%$ of the time (Pica et al., 1989).

Furthermore, attended negative evidence can affect long-term performance. Lightbown and Spada (1990) examined the effects of corrective feedback in the context of intensive communicative ESL teaching in Quebec. Across a range of classrooms, although the teaching was mainly communicative in focus, some teachers paid more attention to the students' formal errors than did others. They found that the learners who received error correction achieved greater accuracy in the production of some structures (e.g. the use of the correct “There is ...” in place of the L1 induced error "It has...”) but not of others (e.g. adjectival placement). Testing done one year later (Lightbown, 1991) revealed continued high performance on "There is/are".

Tomasello and Herron $(1988,1989)$ assessed the efficacy of recastings in SLA. They compared the effects of two kinds of instruction directed at problematic constructions that 
lead to overgeneralisation and transfer errors in early L2 learners of French. In one condition the problems were explained and illustrated to the students. In the 'garden path' condition the typical errors were induced and then recast as corrections. The 'garden path' treatment was more effective and Tomasello \& Herron suggest that this is because the technique allows the learners to carry out cognitive comparison between their own deviant utterances and the correct target-language recasts.

White (1991) examined the effects of explicit instruction on the learning of adverb placement restrictions in English by native speakers of French. The control group was given no information on adverb placement, but was instructed in question formation. The results revealed clear differences between the adverb and question groups. Before instruction, both groups accepted sentences in accordance with French parameter settings (French permits sentences such as Marie regarde souvent la télévision, with the adverb placed between the verb and its direct object, but English does not: *Mary watches often television), accepting SVAO structures as a possible English word order. After instruction, the adverb placement group learned that such sentences are not permitted in English and the question group did not, demonstrating that explicit instruction which included negative evidence was effective in promoting acquisition of this structure, although this effect had disappeared when subjects were retested a year later.

Carroll and Swain (1993) investigated the relative effects of different types of negative feedback on the acquisition of English dative alternation by 100 adult Spanish-speaking learners of ESL. Students were randomly allocated to one of five groups. Upon making an error, Group A were given explicit metalinguistic information about the generalisation that was being taught; Group B were simply told their responses were wrong; Group C were corrected when they erred and given a model of the desired response along with implicit negative evidence that their response was incorrect (this is essentially a recasting condition); Group D, having made an error, were asked if they were sure about their response; the comparison group received no feedback. Subjects were tested twice on the feedback items plus a number of novel items to test for generalisation. All of the feedback groups outperformed the comparison group on the tests, demonstrating that adult L2 learners can and 
do use feedback to learn specific linguistic rules and abstract generalisations and correctly narrow the application of those rules. Moreover, Group A who received negative evidence and general metalinguistic guidance, and Group $\mathrm{C}$ who received negative evidence and a correcting recast, outperformed the other groups.

These studies demonstrate that provision of negative evidence, especially that which incorporates recasts, i.e., responses to utterances that provide corrected or alternative versions, does indeed facilitate the development of L2 syntactic ability. Given the practical demands of naturalistic conversation, frequent negative evidence and properly structured recasts seem much more likely in classroom settings than in the street. However, Oliver (in press) demonstrates in naturalistic native speaker/non-native speaker (NS/NNS) child conversations that (i) NS children modify their interactions for NNS peers by providing reactive and implicit negative feedback to the NNS in the form of (a) negotiation strategies, including repetition, clarification requests and comprehension checks, and (b) recasts; (ii) this negative feedback was incorporated by the NNSs into their interlanguage systems. Thus not only does negative feedback exist for child second language learners in conversations with their NS peers, but also it is also usable and used by them in the language acquisition process.

\section{Conclusions}

Research progress is easiest when positions are cast as black or white - it is easiest to empirically test simple non-interactive hypotheses which hold that a particular variable either results in SLA or does not. But the acquisition of natural languages is a complex interaction of many variables involving cognition, motivation and opportunity for language exposure, use, and feedback. The role of the psychologist is to dissect in order to properly investigate the roles of potential independent variables while controlling all others. It is the opposite of the applied linguist whose job is to synthesise and bring together optimal levels of all of these factors in order to best facilitate SLA. The studies reviewed in this paper have demonstrated that there are roles for explicit learning, for explicit instruction, particularly that which involves grammatical consciousness raising, and for the provision of negative evidence and 
recasts. But each of the experimental demonstrations looked at each factor in isolation and therefore their findings do not imply exclusivity of cause in real-world SLA.

There are differing, additive advantages of different instructional processes and contexts of acquisition. The problem that remains is how best to achieve the best balance. Many aspects of language acquisition are like other skills in that a major predictor is the amount of experience and practice. If, for example, learners are to be fluent in pronunciation then they need lots of practice at pronunciation (N.Ellis, 1994e). An environment which maximises useful experience is one in which there is lots of comprehensible input. Naturalistic environments provide motivation and plenty of opportunity for output practice as well. These are situations which guarantee sufficient quantity of language. But without any focus on form, complete formal accuracy is an unlikely result. The research reviewed here suggests that there are ways of speeding the learners' SLA from a given amount of language exposure, to increase the quality of the learning. These ways, which include grammatical consciousness raising or input processing as well as corrective feedback and recasts, permit the acquisition of sophisticated grammatical proficiency. There is some benefit in a focus on form in second language instruction (see Long, 1988, 1991; Terrell, 1991; R.Ellis, 1994 for reviews of instructional programmes which incorporate these ideas). Even so, it must be remembered that there are constraints on the forms which can be taught at particular stages of linguistic development. Just as there is the issue of Learnability in L1, so there is that of Teachability in L2 - any empirical findings about natural developmental sequences should be respected in the design of instructional materials (Pienemann, 1985), and attempts to teach structures or transformations which build on still-to-be acquired procedures or representations are more likely to fail.

\section{Acknowledgements}

Some of this material is published in our extended review: Ellis, N.C., \& Laporte, N. (in press). Contexts of acquisition: Effects of formal instruction and naturalistic exposure on 
SLA. To appear in A. de Groot \& J. Kroll (Eds.), Tutorials in Bilingualism: Psycholinguistic Perspectives. Hillsdale, N.J.: Lawrence Erlbaum Associates. Its preparation was assisted by a grant from BT (British Telecom) to the FLUENT/RHUGL project.

\section{References}

Alanen, R. (1992). Input enhancement and rule presentation in second language acquisition. Unpublished M.A. thesis, The University of Hawaii at Manoa.

Berry, D.C., \& Broadbent, D.E. (1988). Interactive tasks and the implicit - explicit distinction. British Journal of Psychology, 79, 251-272.

Carroll, S., \& Swain, M. (1993). Explicit and implicit negative feedback. Studies in Second Language Acquisition, 15, 357-386.

Chaudron, C. (1977). A descriptive model of discourse in the corrective treatment of learners' errors. Language Learning, 27, 29-46.

Chomsky, N. (1988). Language and Problems of Knowledge. The Managua Lectures. Cambridge, Mass.: MIT Press.

Crystal, D. (1987). The Cambridge Encyclopedia of Language. Cambridge: Cambridge University Press.

Danks, J. H., \& Gans, D. L. (1975). Acquisition and Utilisation of a Rule Structure. Journal of Experimental Psychology: Human Learning and Memory, 104, 201-208.

De Keyser, R. (in press). Learning second language grammar rules: An experiment with a miniature language system. Studies in Second Language Acquisition, in press.

Dickerson, W. (1984). The role of formal rules in pronunciation instruction. In J. Handscombe, R. Orem \& B. Taylor (Eds.), On TESOL '83 (pp. 135-148). Washinton: TESOL.

Doughty, C. (1991). Second language instruction does make a difference: Evidence from an empirical study of SL relativization. Studies in Second Language Acquisition, 13, 431-469.

Dulany, D. E., Carlson, R. A., \& Dewey, G. I. (1984). A case of syntactical learning and judgement: How conscious and how abstract? Journal of Experimental Psychology: General, 113, 541-555.

Dulay, H., \& Burt, M. (1973). Should we teach children syntax? Language Learning, 23, 245-258. 
Ellis, N.C. (1993). Rules and instances in foreign language learning: Interactions of explicit and implicit knowledge. European Journal of Cognitive Psychology, 5. 289-318.

Ellis, N.C. (Ed.) (1994a). Implicit and Explicit Learning of Languages. London: Academic Press.

Ellis, N.C. (1994b). Implicit and explicit language learning - An overview. In N. Ellis (Ed.), Implicit and Explicit Learning of Languages (pp. 1-32). London: Academic Press.

Ellis, N.C. (1994c). Longitudinal studies of spelling acquisition. In G.D.A. Brown \& N.C. Ellis,(Eds.). Handbook of Spelling: Theory, Process and Intervention (pp. 155-178) Chichester: John Wiley \& Sons Ltd.

Ellis, N.C. (1994d). Consciousness in second language learning: Psychological perspectives on the role of conscious processes in vocabulary acquisition. AILA Review, 11, 37-56.

Ellis, N.C. (1994e). Vocabulary acquisition: The implicit ins and outs of explicit cognitive mediation. In N. Ellis (Ed.), Implicit and Explicit Learning of Languages (pp. 211-282). London: Academic Press.

Ellis, N.C., \& Cataldo, S. (1990). The role of spelling in learning to read. Language and Education, 4, 1-28.

Ellis, N.C., \& Laporte, N. (in press). Contexts of acquisition: Effects of formal instruction and naturalistic exposure on SLA. To appear in A. de Groot \& J. Kroll (Eds.), Tutorials in Bilingualism: Psycholinguistic Perspectives. Hillsdale, N.J.: Lawrence Erlbaum Associates.

Ellis, R. (1984). Can syntax be taught? A study of the effects of formal instruction on the acquisition of WH questions by children. Applied Linguistics, 5, 138-155.

Ellis, R. (1989). Are classroom and naturalistic acquisition the same? A study of the classroom acquisition of German word-order rules. Studies in Second Language Acquisition, 11, 305-328.

Ellis, R. (1990). Instructed Second Language Acquisition. Oxford: Basil Blackwell Ltd.

Ellis, R. (1993). The structural syllabus and second language acquisition. TESOL Quarterly, 27, 91-113.

Ellis, R. (1994). The Study of Second Language Acquisition. Oxford: Oxford University Press.

Esper, E. A. (1925). A Technique for the Experimental Investigation of Associative Interference in Artificial Linguistic Material. Language Monographs. 1, cited in Foss (1968) 
Foss, D. J. (1968). An Analysis of Learning in a Miniature Linguistic System. Journal of Experimental Psychology, 76, 450-459.

Frith, U. (1985). Beneath the surface of developmental dyslexia. In K. Patterson, M. Coltheart and J. Marshall (Eds.) Surface Dyslexia. London: Erlbaum.

Green, P.S., \& Hecht, K. (1992). Implicit and explicit grammar: An empirical study. Applied Linguistics, 13, 168-84.

Hulstijn, J., \& Hulstijn, W. (1984). Grammatical errors as a function of processing constraints and explicit knowledge. Language Learning, 34, 23-43.

Hulstijn, J., \& De Graff, R. (1994). Under what conditions does explicit knowledge of a second language facilitate the acquisition of implicit knowledge? A research proposal. AILA Review, 11, 97-112.

Johnston, M. (1985). Syntactic and Morphological Processes in Learning English. Canberra:

Commonwealth Development of Immigration and Ethnic Affairs.

Krashen, S. (1982). Principles and Practice in Second Language Acquisition. Oxford: Pergamon.

Krashen, S. (1985). The Input Hypothesis: Issues and Implications. London: Longman.

Krashen, S., \& Pon, P. (1975). An error analysis of an advanced ESL learner. Working Papers on Bilingualism, 7, 125-129.

Krashen, S. \& Terrell, T (1983). The Natural Approach: Language Acquisition in the Classroom. Oxford: Pergamon

Lightbown, P. (1983). Exploring relationships between developmental and instructional sequences in L2 acquisition. In H. Seliger \& M. Long (Eds.), Classroom oriented research in second language acquisition (pp. 217-245). Rowley, Mass,: Newbury House.

Lightbown, P. (1991). What have we here? Some observations on the influence of instruction on L2 learning. In R. Phillipson, E. Kellerman, M. Sharwood-Smith, \& M. Swain (Eds.) Foreign/second language pedagogy research (pp. 197-212). Clevedon, England: Multilingual Matters.

Lightbown, P., \& Spada, N. (1990). Focus-on-form and corrective feedback in communicative language teaching: effects on second language learning. Studies in Second Language Acquisition, 12, 429-448. 
Lightbown, P., Spada, N., \& Wallace, R. (1980). Some effects of instruction on child and adolescent ESL learners. In R. Scarcella \& S. Krashen (Eds.), Research in second language acquisition (pp. 162-172). Rowley, Mas.: Newbury House.

Long, M. (1983). Does second language instruction make a difference? A review of research. TESOL Quarterly, 17, 359-382.

Long, M. (1988). Instructed interlanguage development. In L. Beebe (Ed.), Issues in Second Language Acquisition: Multiple Perpectives. New York: Newbury House.

Long, M. (1991). Focus on Form: A design feature in language teaching methodology. In K. de Bot, D. Coste, R. Ginsberg, \& C. Kramsch (Eds.), Foreign Language Research in Cross-Cultural Perspectives. Amsterdam: John Benjamins.

Mathews, R.C., Buss, R.R., Stanley, W.B., Blanchard-Fields, F., Cho, J.-R., \& Druhan, B. (1989). The role of implicit and explicit processes in learning from examples: A synergistic effect. Journal of Experimental Psychology: Learning, Memory, and Cognition, 15, 1083-1100.

Meisel, J., Clahsen, H., \& Pienemann, M. (1981). On determining developmental stages in natural second language acquisition. Studies in Second Language Acquisition, 3, 109135.

Oliver, R. (in press). Negative feedback in child NS/NNS conversation. Studies in Second Language Acquisition.

Perruchet, P., \& Pacteau, C. (1990). Synthetic grammar learning: Implicit rule abstraction or explicit fragmentary knowledge? Journal of Experimental Psychology: General, 119, 264-275.

Pica, T. (1988). Interlanguage adjustments as an outcome of NS-NNS negotiated interaction. Language Learning, 38, 45-73.

Pica, T., Holliday, L., Lewis, N., \& Morgenthaller, L. (1989). Comprehensible output as an outcome of linguistic demands on the learner. Studies in Second Language Acquisition, 11, 63-90.

Pienemann, M. (1984). Psychological constraints on the teachability of languages. Studies in Second Language Acquisition, 6, 186-214.

Pienemann, M. (1985). Learnability and syllabus construction. In K. Hyltenstam \& M. Pienemann (Eds.), Modelling and assessing second language acquisition (pp. 23-75). Clevedon, Avon: Multilingual Matters. 
Pienemann, M. (1986). Is language teachable? Psycholinguistic experiments and hypotheses. Australian Working Papers in Language Development, 1 (3).

Pienemann, M. (1987). Psychological constraints on the teachablity of languages. In C. Pfaff (Ed.), First and second language acquisition processes (pp. 143-168). Cambridge: Newbury House Publishers.

Pienemann, M., Johnston, M., \& Brindley, G. (1988). Constructing an acquisition-based procedure for second language assessment. Studies in Second Language Acquisition, 10, 217-244.

Prabhu, N.S. (1987). Second Language Pedagogy. Oxford: Oxford University Press.

Reber, A. S. (1969). Transfer of Syntactic Structure in Synthetic Languages. Journal of Experimental Psychology, 81, 115-119

Reber, A. S. (1976). Implicit Learning of Synthetic Languages: The Role of Instructional Set.Journal of Experimental Psychology, Human Learning and Memory, 2, 88-94

Reber, A.S. (1993). Implicit Learning and Tacit Knowledge: An Essay on the Cognitive Unconscious. New York: Oxford University Press.

Reber, A. S., Kassin, S. M., Lewis, S., \& Cantor, G. W. (1980). On the relationship between implicit and explicit modes in the learning of a complex rule structure. Journal of Experimental Psychology: Human Learning and Memory, 6, 492-502.

Reber, A.S., \& Lewis, S. (1977). Toward a theory of implicit learning: The analysis of the form and structure of a body of tacit knowledge. Cognition, 5, 333-61.

Rutherford, W. (1987). Grammatical consciousness raising in brief historical perspective. In Rutherford, W. \& Sharwood Smith, M. (Eds.) Grammar and Second Language Teaching. New York: Newbury House.

Schmidt, R. (1990). The role of consciousness in second language learning. Applied Linguistics, 11, 129-158.

Schmidt, R. (1993). Awareness and second language acquisition. Annual Review of Applied Linguistics, 13, 206-226.

Schmidt, R. (1994). Implicit learning and the cognitive unconscious: Of artificial grammars and SLA. In N. Ellis (Ed.), Implicit and Explicit Learning of Languages (pp. 165-210). London: Academic Press.

Schmidt, R. \& Frota, S. (1986). Developing basic conversational ability in a second language: a case study of an adult learner of Portugese. In R. Day (Ed.) Talking to Learn: Conversation in Second Language Acquisition. Rowley, Mass.: Newbury House. 
Schumann, J. (1978). The pidginization process: A model for second language acquisition. Rowley, Mass.: Newbury House.

Seliger, H. (1979). On the nature and function of language rules in language teaching. TESOL Quarterty, 13, 359-369.

Sharwood-Smith, M. (1978). Applied linguistics and the psychology of instruction: A case for transfusion. Studies in Second Language Acquisition, 1, 91-117.

Sharwood-Smith, M. (1981). Consciousness raising and the second-language learner. Applied Linguistics, 2, 159-168.

Sharwood-Smith, M. (1993).Input enhancement in instructed SLA: Theoretical bases. Studies in Second Language Acquisition, 15, 165-179.

Terrell, T. (1991). The role of grammar instruction in a communicative approach. The Modern Language Journal, 75 , 52-63.

Terrell, T., Baycroft, B., \& Perrone, C. (1987). The subjunctive in Spanish interlanguage: accuracy and comprehensibility. In B. VanPatten, T. Dvorak \& J. F. Lee (Eds.), Foreign Language Learning: A Research Perspective (pp. 19-32). Rowley, Mass.: Newbury House.

Tomasello, M., \& Herron, C. (1988). Down the garden path: Inducing and correcting overgeneralisation errors in the foreign language classroom. Applied Psycholinguistics, 9, 237-246.

Tomasello, M., \& Herron, C. (1989). Feedback for language transfer errors: the garden path technique. Studies in Second Language Acquisition, 11, 385-395.

VanPatten, B. (in press). Input processing and SLA: On the relationship between meaning and form. In R. Barrutia, M. van Naerssen \& P. Hashemipour (Eds.), Festschrfit for Tracey David Terrell. New York: McGraw-Hill.

VanPatten, B., \& Cadierno, T. (1993a). Input processing and second language instruction: A Role for Instruction. The Modern Language Journal, 77, 46-57.

VanPatten, B., \& Cadierno, T. (1993b). Explicit instruction and input processing. Studies in Second Language Acquisition, 15, 225-243.

White, L. (1991). Adverb placement in second language acquisition: Some effects of positive and negative evidence in the classroom. Second Language Research, 7, 133-161. 